\title{
PENGELOLAAN LIMBAH KOTORAN TERNAK DALAM UPAYA PENCEGAHAN PENCEMARAN LINGKUNGAN DI KOTA KOTAMOBAGU
}

\author{
Lidyasanty O. Linggotu", U. Paputungan ${ }^{* *}$ dan B. Polii**** \\ *Program Pascasarjana, Universitas Sam Ratulangi, Manado \\ **Fakultas Peternakan, Universitas Sam Ratulangi, Manado \\ ***Fakultas Pertanian, Universitas Sam Ratulangi, Manado
}

\begin{abstract}
ABSTRAK
Limbah usaha peternakan dapat menimbulkan permasalahan lingkungan sekitar pemukiman dimana usaha peternakan berada, jika tidak dikelola dengan baik. Tujuan penelitian ini adalah mengevaluasi apakah tingkat pengetahuan, sikap dan keterampilan teknis para peternak merupakn faktor penting dalam upaya kegiatan penanganan pencemaran limbah kotoran ternak di wilayah Kota Kotamobagu. Variabel dalam penelitian ini terdiri dari pengetahuan (X1), sikap/perilaku (X2), keterampilan teknis (X3) dan upaya pengelolaan limbah kotoran ternak oleh para peternak $(\mathrm{Y})$, yang dianalisis menggunakan regresi linear berganda dengan model matematis $\mathbf{Y}_{\mathbf{i}}=\mathbf{b}_{\mathbf{0}}+\mathbf{b}_{\mathbf{1}} \mathbf{X}_{\mathbf{1}}+\mathbf{b}_{\mathbf{2}} \mathbf{X}_{\mathbf{2}}+\mathbf{b}_{\mathbf{3}} \mathbf{X}_{\mathbf{3}}+\mathbf{e}_{\mathbf{i}}$; dimana $Y_{i}$ adalah pengamatan keputusan peternak dalam proses kegiatan penanganan limbah kotoran ternak ke-i; $b_{0}$ adalah intercept; $b_{1}, b_{2}$ dan $b_{3}$ adalah koefisien regresi, $X_{1}$ adalah pengetahuan peternak, $X_{2}$ adalah sikap peternak, $\mathrm{X}_{3}$ adalah keterampilan teknis peternak dalam penanganan pencemaran lingkungan dan $\mathrm{e}_{1}$ adalah random error. Hasil penelitian ini menunjukkan bahwa tingkat pengetahuan $\left(\mathrm{X}_{1}\right)$, sikap $\left(\mathrm{X}_{2}\right)$ dan keterampilan teknis $\left(\mathrm{X}_{3}\right)$ oleh para peternak merupakan faktor penting yang mempengaruhi upaya kegiatan penanganan pencemaran lingkungan dari limbah kotoran ternak (Y) di
\end{abstract}

Korespondensi (corresponding author):

Email: umarfapet@yahoo.com wilayah Kota Kotamobagu. Model persamaan regresi linear berganda diperoleh $\mathrm{Y}=1.468+$ $0,784 X_{1}+0,218 X_{2}+0,004 X_{3}$. Koefisien determinan $\left(\mathrm{R}^{2}\right) 0,81$, yang berarti bahwa 81 persen variasi variabel bebas $\left(\mathrm{X}_{1}, \mathrm{X}_{2}, \mathrm{X}_{3}\right)$ yang digunakan dalam model ini mampu menjelaskan variasi variabel tidak bebas $(\mathrm{Y})$. Nilai rata-rata skor variabel pengetahuan $\left(X_{1}=87,23\right)$, sikap $\left(X_{2}=93,37\right)$, keterampilan teknis $\left(\mathrm{X}_{3}=88,40\right)$ dan upaya kegiatan $(\mathrm{Y}=90,60)$ dalam penanganan pencemaran lingkungan dari limbah kotoran ternak ayam dan ternak babi di Kota Kotamobagu masih berada sedikit di bawah nilai-nilai skor median $\left(X_{1}=93 ; \quad X_{2}=100 ; \quad X_{3}=100 ; \quad Y=93\right) \quad$ dari variabel-variabel tersebut. Kondisi ini menyarankan perlu dilakukan penyuluhan ke arah perbaikan dan peningkatan pengetahuan, sikap, dan keterampilan teknis serta upaya kegiatan dalam penanganan pencemaran lingkungan yang bersumber dari limbah kotoran ternak, terutama kepada para peternak yang masih memiliki pengetahuan, sikap, keterampilan teknis serta upaya penanganan pencemaran lingkungan yang masih rendah.

Kata Kunci: Limbah kotoran ternak,
pencegahan
lingkungan, Kota Kotamobagu




\section{ABSTRACT}

ANIMAL WASTE PRODUCT
MANAGEMENT FOR PREVENTION OF
ENVIRONMENTAL POLLUTION IN
KOTAMOBAGU CITY. The animal wastes
from animal farm affect the environmental condition of human settlement, when it was not well managed. The objectives of this study was to evaluate either levels of knowledge, attitude and technical skill had correlated directly or not with their motivation activity in preventing environmental pollution of animal wastes around Kotamobagu city. Variables in this study were referring on the farmer's standard knowledge $\left(\mathrm{X}_{1}\right)$, attitude $\left(\mathrm{X}_{2}\right)$, technical skill $\left(\mathrm{X}_{3}\right)$ and motivation activity in preventing environmental pollution of animal wastes (Y) around Kotamobagu city using the functions of linear multiple regression, $\mathbf{Y}_{\mathbf{i}}=\mathbf{b}_{\mathbf{0}}$ $+\mathbf{b}_{1} \mathbf{X}_{1}+\mathbf{b}_{2} \mathbf{X}_{2}+\mathbf{b}_{3} \mathbf{X}_{3}+\mathbf{e}_{i}$; where $Y_{\mathrm{i}}$ was the-i observation of farmer's motivation activity in preventing environmental pollution of animal wastes; $b_{0}$ was intercept; $b_{1}, b_{2}$ and $b_{3}$ were regression coefficients, $X_{1}$ was farmer's knowledge, $\mathrm{X}_{2}$ farmer's attitude, $\mathrm{X}_{3}$ was farmer's technical skill in preventing environmental pollution of animal wastes; and $\mathrm{e}_{1}$ was random error. Results of this study showed that knowledge level $\left(\mathrm{X}_{1}\right)$, attitude $\left(\mathrm{X}_{2}\right)$ and technical skill $\left(\mathrm{X}_{3}\right)$ of farmers could be the important factors affecting farmer's motivation activity in preventing environmental pollution of animal wastes (Y) in Kotamobagu city areas. The equation of multiple regression model was found, $\mathrm{Y}=$ $1.468+0.784 X_{1}+0.218 X_{2}+0.004 X_{3}$. The determination coefficient $\left(\mathrm{R}^{2}\right)$ of 0.81 in this model indicated that 81 percents of the variation of independent variables $\left(\mathrm{X}_{1}, \mathrm{X}_{2}\right.$, and $\mathrm{X}_{3}$ ) used in the model were able to affect the variation of the dependent variable $(Y)$. The rest of 19 percents in the model were caused by the other unknown factors. The average score values of knowledge level $\left(X_{1}=87.23\right)$, attitude $\left(X_{2}=93.37\right)$ and technical skill $\left(\mathrm{X}_{3}=88.40\right)$ and farmer's motivation activity $(\mathrm{Y}=90.60)$ in preventing environmental pollution of animal wastes (poultry and pig) in Kotamobagu city areas were still below the score median values $\left(X_{1}=93 ; X_{2}=100 ; X_{3}=100\right.$; $Y=93$ ) of those variables. This condition suggested that extension activities related to the prevention of environmental pollution of animal wastes in Kotamobagu city areas were still needed to be conducted, mainly to the farmers with low scores in knowledge, attitude, technical skill and motivation activity in preventing environmental pollution of animal wastes.

Key words: Animal waste product, prevention of environmental pollution, Kotamobagu city.

\section{PENDAHULUAN}

Pencemaran lingkungan oleh sebuah usaha peternakan apapun tidak mungkin dihindari. Isu pencemaran lingkungan sering menimbulkan keresahan di tengah masyarakat, terutama jika lokasi peternakan dekat dengan pemukiman (Rosenberg, et. al., 1998; Vigne, 2009). Namun, dampak pencemaran lingkungan mestinya bisa diminimalisir jika usaha peternakan dikelola dengan baik. Untuk itu, Pemerintah Daerah harus memainkan perannya secara maksimal untuk pembinaan, pengawasan, dan penertiban usaha peternakan. Lemahnya pengawasan oleh Dinas terkait bisa memicu konflik horizontal di tengah masyarakat. 
Selama ini banyak keluhan masyarakat akan dampak buruk dari kegiatan usaha peternakan karena sebagian besar peternak mengabaikan penanganan limbah dari usahanya, bahkan ada yang membuang limbah usahanya ke sungai, sehingga terjadi pencemaran lingkungan. Limbah peternakan yang dihasilkan oleh aktivitas peternakan seperti feces, urin, sisa pakan, serta air dari pembersihan ternak dan kandang menimbulkan pencemaran yang memicu protes dari warga sekitar, baik berupa bau tidak enak yang menyengat, sampai keluhan gatal-gatal ketika mencuci di sungai yang tercemar limbah peternakan (Funk, 2007).

Seiring bertambahnya penduduk dan minimnya lahan pertanian, banyak petani dan pengusaha ternak yang menempatkan lahan pertanian dan peternannya disekitar rumah penduduk, lebihnya lagi dekat dengan area sekolah. Lalu bagaimana dengan peternak sapi dan pengaruh limbahnya yang dekat dengan tempat-tempat yang telah disebutkan sebelumnya. Oleh karena itu, seiring dengan kebijakan otonomi, maka pemgembangan usaha peternakan yang dapat meminimalkan limbah peternakan perlu dilakukan oleh pemerintah kabupaten/kota untuk menjaga kenyamanan permukiman masyarakatnya. Salah satu upaya kearah itu adalah dengan memanfaatkan limbah peternakan sehingga dapat memberi nilai tambah bagi usaha tersebut (Murdiati, dkk., 1995; Palgunadi, dkk., 1999).

Dalam kasus pencemaran lingkungan oleh peternakan ayam, yang menjadi pemicu permasalahan sebenarnya adalah akibat dari pemukiman yang terus berkembang. Pada awal pembangunan, peternakan ayam didirikan jauh dari pemukiman penduduk namun lama kelamaan di sekitar areal petemakan tersebut menjadi pemukiaman. Hal tersebut dapat terjadi karena perkembangan dan rencana tataruang yang tidak konsisten (Infovet, 1996, Setiawan, 1996). Untuk itu, perlu suatu perbaikan sistem pemanfaatan lahan yang sesuai dengan peruntukannya. Dalam hal ini pemerintah membuat kebijakan penggunaan suatu areal atau kawasan usaha peternakan agar tidak saling mengganggu antara petemakan dan pemukiman. Sudah tentu kawasan tersebut juga harus senantiasa memelihara lingkungannya, antara lain dengan melakukan pengelolaan limbah serta pemantauan lingkungan secara terus menerus. Tujuan penelitian ini adalah mengevaluasi apakah tingkat pengetahuan, sikap dan keterampilan teknis oleh para peternak dapat merupakan faktor penting yang mempengaruhi upaya kegiatan 
penanganan pencemaran lingkungan dari limbah kotoran ternak di wilayah Kota Kotamobagu.

\section{MATERI DAN METODE PENELITIAN}

Penelitian ini dilakukan di wilayah lokasi peternakan yang berada di Kota Kotamobagu. Pemilihan lokasi didasarkan pada pemahaman bahwa implementasi kebijakan pananganan lingkungan sehat di wilayah Kota Kotamobagu khususnya pengelolaan limbah peternakan dilaksanaan oleh peternak itu sendiri dengan mengacuh pada aturan pemerintah tentang pengawasan lingkungan usaha peternakan yang sehat. Penelitian ini dilaksanakan pada bulan Mei sampai dengan Juni 2015 di empat Kecamatan, yaitu Kecamatan Kotamobagu Timur, Kecamatan Kotamobagu Barat, Kecamatan Kotamobagu Utara dan Kecamatan Kotamobagu Selatan.

Penelitian ini menggunakan rancangan data kualitatif dikonversi ke data kuantitatif dengan memberikan nilai skoring data dan menggunakan analisis dengan pendekatan induktif. Dalam penelitian kualitatif peneliti bertolak dari data berdasarkan kajian hasil survey, wawancara dan dokumen aturan-aturan pengelolaan lingkungan, memanfaatkan teori yang ada sebagai bahan penjelas, dan berakhir dengan suatu "teori" (Moleong,
2012). Selanjutnya dijelaskan bahwa desain kualitatif merupakan prosedur penelitian yang menghasilkan data deskriptif berupa kata-kata tertulis atau lisan dari orang-orang dan prilaku yang dapat diamati. Pemdekatan kualitatif dicirikan oleh tujuan penelitian yang berupaya memahami gejala-gejala yang tidak memerlukan kuantifikasi, karena gejala tidak memungkinkan untuk diukur secara tepat (Creswell, 2002). Hal ini sejalan dengan tujuan penelitian yang telah dikemukakan, yaitu menganalisis implementasi pengelolaan limbah kotoran ternak dalam upaya pencegahan pencemaran lingkungan di Kota Kotamobagu.

Sumber data dalam penelitian ini adalah data primer dan data sekunder. Data primer adalah data yang langsung diperoleh peneliti dengan melakukan wawancara kepada informan dan pengamatan langsung di lapang. Data sekunder adalah data pendukung lainnya yang diperlukan seperti laporan kerja, aturan-aturan dan data lainnya yang berhubungan dengan objek penelitian. Dengan demikian, data primer diperoleh melalui wawancara kepada informan yang berada di wilayah Kota Kotamobagu, yaitu: 1)Peternak yang mengusahakan peternakan ayam, 2) Peternak yang mengusahakan peternakan babi, 3) Pekerja kandang ternak ayam, 4) Pekerja kandang 
ternak babi, dan 5) Warga masyarakat tinggal di dekat areal peternakan ayam dan warga masyarakat tinggal di dekat areal peternakan babi.

Variabel dalam penelitian ini adalah mengacuh pada pengetahuan, sikap/prilaku, tindakan teknis dan upaya penanganan limbah kotoran ternak oleh para peternak, yang disesuaikan Moleong (2012), yaitu 1) Pengetahuan peternak tentang penanganan bau dan infeksi $\mathrm{m}$. organisme dari kandang ternak (Cognitif), yaitu dikategorikan:

a) Baik, jika diperoleh nilai $>75 \%$ dari total maksimum skor 15

b) Sedang, jika diperoleh nilai berkisar 51

$-75 \%$ dari total maksimal skor 15

c) Kurang, jika diperoleh nilai $<50 \%$ dari total maksimal skor 15.

2) Sikap/prilaku peternak terhadap penanganan bau dan infeksi (afektif), yaitu dikategorikan:

a) Sikap Positif, jika diperoleh nilai > Nilai median

b) Sikap Negatif, jika diperoleh nilai $\leq$ Nilai median.

3) Keterampilan teknis penanganan bau limbah kotoran ternak dan infeksi mikroorganisme, yaitu dikategorikan:

a) Teknis Baik, jika diperoleh nilai > Nilai median b) Teknis Kurang Baik, jika diperoleh nilai $\leq$ Nilai median.

4) Upaya kegiatan penanganan bau dan infeksi pernafasan manusia yang berada di areal kandang ternak, yaitu dikategorikakan:

a) Baik, jika diperoleh nilai $>75 \%$ dari total maksimum skor 15

b) Sedang, jika diperoleh nilai berkisar 51

$-75 \%$ dari total maksimal skor 15

c) Kurang, jika diperoleh nilai $<50 \%$ dari total maksimal skor 15.

Berdasarkan teori yang dikemukakan oleh Smith, (1973), Sitorus (2006) dan Moleong (2012), maka konsep penelitian dapat digambarkan dengan model variabel-variabel sebagai berikut:

1. Variabel Independent. Yang termasuk variabel independent (variabel bebas) adalah pengetahuan, sikap, dan keterampilan teknis penanganan limbah kotoran ternak.

2. Variabel Dependen. Yang termasuk Variabel Dependen (variabel terikat) adalah upaya kegiatan penanganan pencemaran bau dan penyakit infeksi yang menunjang lingkungan hidup yang sehat.

Analisis statistik yang digunakan dalam penelitian ini adalah analisis regresi linear berganda dengan rumus (Byrkit, 1987). Persamaan estimasi untuk varaibel tidak bebas (dependent) dari sifat-sifat lain sebagai variabel bebas (independent) 
ditetapkan dalam persamaan ini. Analisis regresi dan statistik deskriptif variabel tidak bebas (Y) terhadap setiap variabel bebas $\left(\mathrm{X}_{1}, \mathrm{X}_{2}, \mathrm{X}_{3}\right)$ diperoleh melalui prosedur statistik dalam datasheet Microsoft Office Excel 2007 dikaitkan model regresi berganda yang digambarkan oleh Byrkit (1987).

Fungsi regresi linear dari tiga variabel bebas $\left(\mathrm{X}_{1}, \mathrm{X}_{2}, \mathrm{X}_{3}\right)$ terhadap variabel tidak bebas (Y) dimasukkan dalam model persamaan sebagai berikut:

$Y_{i}=b_{0}+b_{1} X_{1}+b_{2} X_{2}+b_{3} X_{3}+e_{i}$

Dimana $Y_{i}$ adalah pengamatan keputusan peternak dalam proses kegiatan penanganan limbah kotoran ternak ke-i; $b_{0}$ adalah intercept; $b_{1}, b_{2}$ dan $b_{3}$ adalah koefisien regresi, $X_{1}$ adalah pengetahuan peternak, $X_{2}$ adalah sikap peternak, $X_{3}$ adalah keterampilan teknis peternak dalam penanganan pencemaran lingkungan dan $e_{1}$ adalah random error (Byrkit, 1987).

\section{HASIL DAN PEMBAHASAN}

\section{Tingkat Pengetahuan Peternak Terhadap Penanganan Lingkungan}

Tingkat pengetahuan para peternak terhadap penanganan lingkungan dari limbah kotoran ternak dikategorikan sangat baik, jika nilai pengetahuan lebih besar dari angka median, dan dikategorikan masih kurang baik jika nilai pengetahuan sama atau kurang dari angka median (Moleong, 2012). Skor rata-rata dan skor median untuk pengetahuan peternak $\left(\mathrm{X}_{1}\right)$ terhadap penanganan limbah kotoran ternak dapat terlihat pada "Bar Chart" yang ada pada Gambar 1.

Nilai skor angka rata-rata pengetahuan peternak terhadap penanganan lingkungan dari limbah kotoran ternak ayam petelur adalah sebesar 92,4 dan limbah kotoran ternak babi sebesar 96 (Gambar 1). Nilai rata-rata dari kedua usaha peternakan ini masih berada dibawah nilai median $93 \quad(92,4<93)$ untuk ayam petelur dan nilai median $100 \quad(96<100)$ untuk ternak babi. Dengan demikian, ratarata tingkat pengetahuan para peternak ayam petelur dan peternak babi masih kurang dari harapan secara keseluruhan dalam hal penanganan limbah kotoran ternak guna menunjang lingkungan yang sehat.

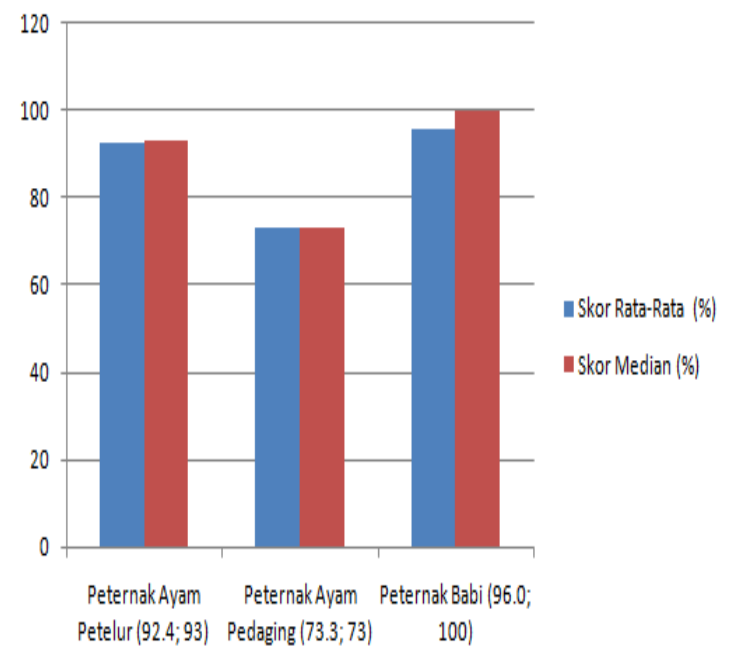

Gambar 1. Skor Rata-Rata dan Skor Median Untuk Pengetahuan Peternak $\left(\mathrm{X}_{1}\right)$ Terhadap Penanganan Limbah Kotoran Ternak 
Nilai angka rata-rata pengetahuan peternak terhadap penanganan lingkungan dari limbah kotoran ternak ayam pedaging adalah sebesar 73,3 (Gambar 1). Nilai ratarata dari usaha peternakan ayam pedaging ini berada diatas nilai median $73(73,3>$ 73). Dengan demikian, rata-rata tingkat pengetahuan para peternak ayam pedaging dapat sesuai harapan secara keseluruhan dalam hal penanganan limbah kotoran ternak guna menunjang lingkungan yang sehat. Dari Gambar 1 di atas, terlihat bahwa nilai pengetahuan (cognitif) peternak tentang penanganan sumber pencemaran bau dan infeksi mikroorganisme di Kota Kotamobagu dapat dikategorikan baik, karena peternak ayam petelur, ayam pedaging dan peternak babi semuanya melebihi nilai 75 persen dari skor maksimum.

\section{Sikap Peternak Terhadap Penanganan Peternakan Lingkungan}

Sikap atau prilaku (afektif) peternak sebagai responden terhadap penanganan lingkungan dari pencemaran bau limbah kotoran ternak diobservasi pada usaha peternakan ayam petelur, ayam pedaging dan peternakan babi dengan menggunakan kuesioner berisi pertanyaanpertanyaan yang meliputi kecendrungan memberi pendapat atau tanggapan (positif atau negatif) terhadap pencemaran bau limbah kotoran ternak. Bentuk-bentuk pertanyaan adalah bersifat memilih jawaban yang sudah disediakan untuk dijawab peternak guna pengetahui tingkat pengetahuan mereka dengan kuesioner. Skor rata-rata dan skor median untuk sikap peternak $\left(\mathrm{X}_{2}\right)$ terhadap penanganan limbah kotoran ternak dapat terlihat pada "Bar Chart" yang ada pada Gambar 2.

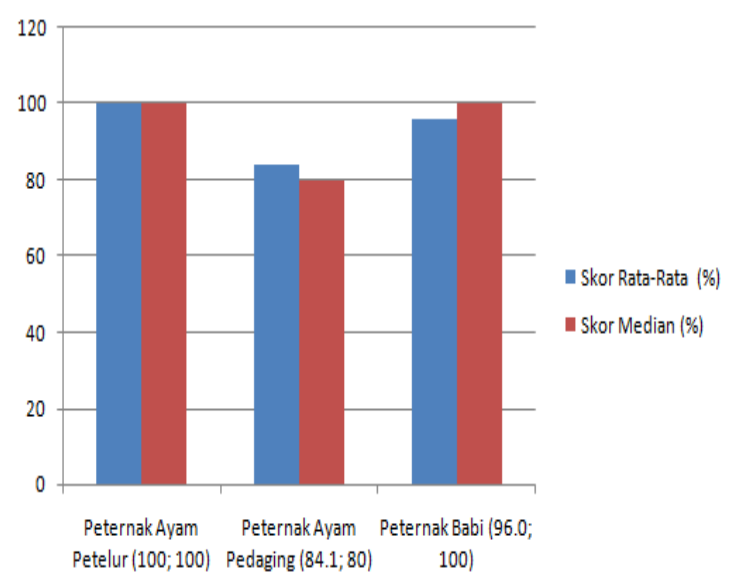

Gambar 2. Skor Rata-Rata dan Skor Median Untuk Sikap Peternak $\left(\mathrm{X}_{2}\right)$ Terhadap Penanganan Limbah Kotoran Ternak

Menurut Kamal (2001), sikap dibedakan atas Sikap positif, yaitu sikap yang menunjukkan atau yang memperlihatkan menerima, mengakui, menyetujui serta melaksanakan normanorma yang berlaku dimana individu itu berada. Sedangkan Sikap negatif, yaitu sikap yang menunjukkan atau memperlihatkan penolakan atau tidak menyetujui terhadap norma-norma yang berlaku dimana individu berada. Seseorang 
mempunyai sikap aktif, yaitu selalu berusaha untuk hidup dengan lebih baik, akan tetapi seseorang yang sifatnya apatis akan menerima apa adanya dan tidak mempunyai pilihan dan pertimbangan, sikap seperti itu sangat rendah motifasinya untuk berkembang dan ingin maju (Sitorus, 2006).

Nilai angka rata-rata sikap peternak terhadap penanganan lingkungan dari limbah kotoran ternak ayam petelur, ayam pedaging dan ternak babi ini semua berada dibawah nilai median 100. Dengan demikian, rata-rata sikap/prilaku para peternak ayam petelur, ayam pedaging dan babi masih perlu menyesuaikan dengan harapan secara keseluruhan dalam hal penanganan limbah kotoran ternak guna menunjang lingkungan yang sehat, terutama bagi peternak yang masih memiliki skor minimum.

\section{Keterampilan Teknis Penanganan Terhadap Lingkungan Peternakan Di Kota Kotamobagu}

Keterampilan teknis oleh peternak sebagai responden terhadap penanganan lingkungan dari pencemaran bau limbah kotoran ternak diobservasi pada usaha peternakan ayam petelur, ayam pedaging dan peternakan babi dengan menggunakan kuesioner berisi pertanyaan-pertanyaan yang meliputi kecendrungan keterampilan teknis terhadap pencemaran bau limbah kotoran ternak. Skor rata-rata dan skor median untuk keterampilan teknis peternak $\left(\mathrm{X}_{3}\right)$ terhadap penanganan limbah kotoran ternak dapat terlihat pada "Bar Chart" yang ada pada Gambar 3.

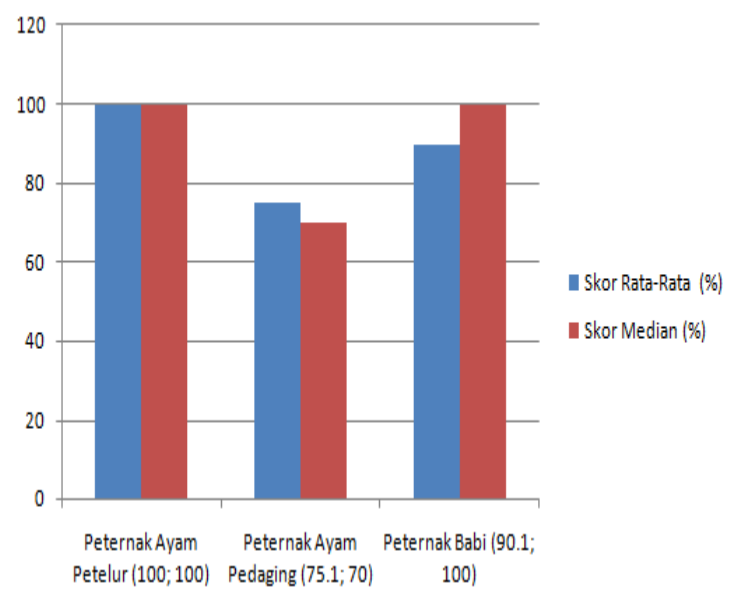

Gambar 3. Skor Rata-Rata dan Skor Median Untuk Keterampilan Teknis Peternak $\left(\mathrm{X}_{3}\right)$ Terhadap Penanganan Limbah Kotoran Ternak.

Keterampilan teknis para peternak terhadap penanganan lingkungan dari limbah kotoran ternak dikategorikan baik, jika nilai tindakan teknis lebih besar dari angka median, dan dikategorikan kurang baik, jika nilai pengetahuan sama atau kurang dari angka median (Moleong, 2012). Nilai angka rata-rata keterampilan teknis peternak terhadap penanganan lingkungan dari limbah kotoran ternak ayam petelur adalah sebesar 100; limbah kotoran ayam pedaging 75,1 dan limbah kotoran ternak babi sebesar 90,1 (Gambar 3). Nilai rata-rata dari ketiga usaha peternakan babi masih berada dibawah nilai 
median $100(90,1<100)$, sedangkan untuk ayam petelur sama dengan nilai median 100 dan untuk ayam pedaging masih lebih tinggi dari nilai median $70 \quad(75.1>70)$. Dengan demikian, rata-rata nilai untuk keterampilan teknis para peternak ayam petelur dan ayam pedaging sudah memenuhi harapan dalam penanganan limbah, yaitu kandang berada di atas kolam dan peternak babi masih kurang dari harapan secara keseluruhan dalam hal penanganan limbah kotoran ternak guna menunjang lingkungan yang sehat.

\section{Upaya Penanganan Pencemaran Lingkungan Peternakan Di Kota Kotamobagu}

Upaya oleh peternak sebagai responden terhadap penanganan lingkungan dari pencemaran bau limbah kotoran ternak diobservasi pada usaha peternakan ayam petelur, ayam pedaging dan peternakan babi dengan menggunakan kuesioner berisi pertanyaan-pertanyaan yang meliputi upaya terhadap penanganan pencemaran bau limbah kotoran ternak. Bentuk-bentuk pertanyaan adalah bersifat memilih jawaban yang sudah disediakan untuk dijawab peternak guna pengetahui tingkat pengetahuan mereka dengan kuesioner. Nilai skor angka rata-rata upaya kegiatan peternak terhadap penanganan lingkungan dari limbah kotoran ternak ayam petelur adalah sebesar 97,2; limbah kotoran ayam pedaging sebesar 76.0 dan limbah kotoran ternak babi sebesar 98,6. Skor rata-rata dan skor median untuk kegiatan (Y) peternak terhadap penanganan limbah kotoran ternak dapat terlihat pada "Bar Chart" (Gambar 4).

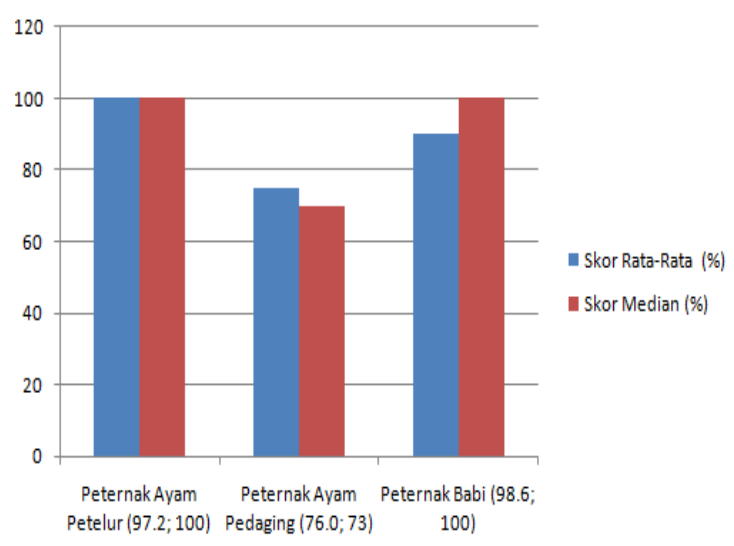

Gambar 4. Skor Rata-Rata dan Skor Median Untuk Kegiatan (Y) Peternak Terhadap Penanganan Limbah Kotoran Ternak

Nilai skor rata-rata dari kedua usaha peternakan ayam dan babi masih berada dibawah nilai median dari masing-masing peternakan secara berurut, yaitu ayam petelur 97,2 (rata-rata 97,2 < median 100) dan ternak babi 98,6 (rata-rata 98,6 < median100). Untuk usaha peternakan ayam daging berada di atas nilai median (rata-rata 76> median 73). Dengan demikian, rata-rata upaya kegiatan para peternak ayam petelur dan peternak babi masih kurang dari harapan secara keseluruhan dalam hal penanganan limbah kotoran ternak guna menunjang lingkungan yang sehat. Untuk itu, upaya kegiatan penanganan limbah ternak oleh 
para peternak masih perlu terus ditingkatkan dalam menunjang lingkungan usaha peternakan yang sehat dan bersih.

\section{Hubungan Kesadaran Masyarakat Peternak (Pengetahuan, Sikap Dan Keterampilam Teknis) Dengan Upaya Penanganan Lingkungan}

Kesadaran masyarakat peternak dapat diukur melalui faktor pengetahuan peternak, sikap peternak, dan keterampilan teknis $\left(\mathrm{X}_{3}\right)$ yang diterapkan peternak dalam upaya kegiatan penanganan lingkungan sehat (Y) secara khusus dari limbah kotoran ternak. Berdasarkan teori yang dikemukakan oleh Sitorus (2006), maka dalam konsep penelitian ini, faktorfaktor yang termasuk variabel independent (variabel bebas) adalah pengetahuan peternak $\left(\mathrm{X}_{1}\right)$, sikap peternak $\left(\mathrm{X}_{2}\right)$, dan keterampilan teknis $\left(\mathrm{X}_{3}\right)$ dalam penanganan limbah kotoran ternak. Faktor yang termasuk variabel dependen (variabel terikat) adalah upaya kegiatan penanganan pencemaran lingkungan $(\mathrm{Y})$ termasuk bau dan penyakit infeksi guna menunjang lingkungan hidup yang sehat.

Menurut Kamal (2001), sikap dibedakan atas: 1) Sikap positif, yaitu sikap yang menunjukkan atau yang memperlihatkan menerima, mengakui, menyetujui serta melaksanakan normanorma yang berlaku dimana individu itu berada; 2) Sikap negatif, yaitu sikap yang menunjukkan atau memperlihatkan penolakan atau tidak menyetujui terhadap norma-norma yang berlaku dimana individu berada. Seseorang mempunyai sikap aktif, yaitu selalu berusaha untuk hidup dengan lebih baik, akan tetapi seseorang yang sifatnya apatis akan menerima apa adanya dan tidak mempunyai pilihan dan pertimbangan, sikap seperti itu sangat rendah motifasinya untuk berkembang dan ingin maju (Sitorus, 2006).

Untuk tiga variabel prediktor $\left(\mathrm{X}_{1}\right.$, $\mathrm{X}_{2}$ dan $\mathrm{X}_{3}$ ) dan satu variabel respon $(\mathrm{Y})$, sesuai persamaan normal (Byrkit, 1987) dianalisis hubungan dalam model persamaan regresi berganda dengan menggunakan skor nilai pada masingmasing faktor dengan hasil model persamaan adalah seperti berikut:

\section{$Y=1.46776+0,78447 X_{1}+0,21793 X_{2}+$ $\mathbf{0 , 0 0 4} \mathbf{X}_{3}$}

Model persamaan regresi berganda ini memiliki angka koefisien determinan $\left(\mathrm{R}^{2}\right)$ sebesar 0,81. Angka koefisien determinan $\left(\mathbf{R}^{\mathbf{2}}\right)$ digunakan untuk mengetahui persentase sumbangan pengaruh variabel bebas $\left(\mathrm{X}_{1}, \mathrm{X}_{2}, \mathrm{X}_{3}\right)$ secara serentak terhadap variabel tidak bebas (Y) (Byrkit, 1987). Koefisien determinan dalam kajian ini menunjukkan bahwa 81 persen variasi variabel bebas $\left(\mathrm{X}_{1}, \mathrm{X}_{2}, \mathrm{X}_{3}\right)$ yang digunakan dalam model ini mampu menjelaskan variasi variabel tidak bebas (Y). 
Selanjutnya untuk setiap penambahan 1 unit skor variable $\mathrm{X}_{1}$ (pengetahuan peternak), maka rata-rata perubahan unit skor variabel Y (upaya kegiatan penanganan pencemaran lingkungan) diperkirakan bertambah sebesar $0,78447\left(b_{1}\right)$, jika jumlah unit skor variabel $\mathrm{X}_{2}$ (sikap peternak) dan $\mathrm{X}_{3}$ (keterampilan teknis peternak) tetap kostan. Untuk setiap penambahan 1 unit skor variable $\mathrm{X}_{2}$ (sikap peternak), maka rata-rata perubahan unit skor variabel $\mathrm{Y}$ (upaya kegiatan penanganan pencemaran lingkungan) diperkirakan bertambah sebesar 0,21793 $\left(b_{2}\right)$, jika jumlah unit skor variabel $\mathrm{X}_{1}$ (pengetahuan peternak) dan $\mathrm{X}_{3}$ (keterampilan teknis peternak) tetap kostan.

\section{KESIMPULAN}

Kesimpulan penelitian ini adalah sebagai berikut:

1. Kesadaran masyarakat peternak ayam dan peternak babi dalam bentuk pengetahuan (rata-rata skor 87,23 persen), sikap (rata-rata skor 93,37 persen) dan ketarmpilan teknis (rata-rata skor 88,4 persen) telah masuk pada kategori sangat baik (> 75 persen) dalam upaya penanganan lingkungan yang sehat pada usaha peternakan di wilayah Kota Kotamobagu.
2. Limbah kotoran ternak dalam usaha peternakan (ternak ayam dan ternak babi) selalu dapat diupayakan oleh peternak (rata-rata skor 90,6 persen) berdasarkan standar pengetahuan, sikap dan tindakan teknis penanganan sehingga masuk dalam kategori sangat baik dalam menunjang lingkungan yang bersih dan sehat bagi masyarakat di wilayah Kota Kotamobagu.

3. Tingkat pengetahuan, sikap dan keterampilan teknis oleh para peternak dapat merupakan faktor penting $\left(\mathrm{R}^{2}=\right.$ 0,81 ) yang mempengaruhi upaya kegiatan penanganan pencemaran lingkungan dari limbah kotoran ternak di wilayah Kota Kotamobagu.

\section{DAFTAR PUSTAKA}

Byrkit, D.R. 1987. Statistics Today: A Comprehensive Introduction. The Benjamin/Cummings Publishing Company, Inc. 2727 Sand Hill Road Menlo Park, California, 94025, USA.

Creswell, J.W. 2002. Research Design Qualitative and Quantitative Approaches; Alih Bahasa: Angkatan III dan IV KIK-UI dan Bekerjasama dengan Nur Khabibah, Jakarta: KIK Press.

Funk, E.A 2007. The pygmy hog is a unique genus: 19th century taxonomists got it right first time round. Molecular Phylogenetics and Evolution, Volume 45: 427-436

Infovet. 1996. Membangun peternakan yang akrab lingkungan, Informasi Dunia Kesehatan Hewan. Edisi 37: 8-11. 
Kamal, M. 2001. Pengetahuan Sikap Dan Tindakan Para Medis Di Ruang SMF Bedah RSU Zainoel Abidin Banda Aceh Terhadap Infeksi Nosokomial Pada Pasien Post Operasi. Laporan, FKM Unmuh Banda Aceh.

Moleong, LJ. 2012. Metode Penelitian Kualitatif. Edisi Revisi. Bandung.

Murdiati, T.B., S. Rachmawati, dan E. Juapini. 1995. Zeolit untuk mengurangi bau dari kotoran ayam. Prosiding Seminar Nasional Peternakan dan Veteriner. Pusat Penelitian dan Pengembangan Petemakan. Badan Penelitian dan Pengembangan Pertanian. Departemen Pertanian, Jilid 2: 991-998.

Palgunadi, N.W.L., M. Sudarwanto, L. Barka, dan E.S. Pribadi. 1999. Penambahan mikroba pengurai limbah pada kotoran untuk menurunkan kadar gas amonia dan hidrogen sulfida di peternakan babi di Bali. Media Veteriner (Majalah Ilmu Kedokteran Veteriner Indonesia). 6(1): 15-18.

Rosenberg, M., R. Nesbitt, R.W. Redding, and B.L. Peasnall. 1998. Hallan Cemi, pig husbandry, and postPleistocene adaptations along the Taurus-Zagros Arc (Turkey). Paleorient, 24(1): 25-41.

Setiawan, H. 1996. Amonia, sumber pencemar yng meresahkan. Dalam: Infovet (Informasi Dunia Kesehatan Hewan). Edisi 37: 12.

Sitorus, B. 2006. Model Praktek Keperawatan Profesional Di Rumah Sakit, Jakarta; Penerbit Buku Kedokteran.

Smith, T.B. 1973. The Policy Implementation Process. Policy Sciences, Vol. 4: 197-209.
Vigne, J.D. 2009. Pre-Neolithic wild boar management and introduction to Cyprus more than 11,400 years ago. Proc Natl Acad Sci U S A. 106:16135-16138. PMID 19706455 doi:10.1073/pnas.0905015106 